\title{
Unit cost of providing and utilizing contraception services for newly married couples in Satara district of Maharashtra, India
}

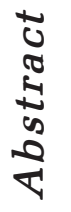

\section{Swapnil Vishnu Lale', Asha K. Pratinidhi ${ }^{2}$}

${ }^{1}$ Ph.D Student, Department of Community Medicine, ${ }^{2}$ Director of Research, Krishna Institute of Medical Sciences Deemed University, Karad, Satara, Maharahstra, India

Address for the Correspondence: Dr. Swapnil Vishnu Lale, A-4, Chintamanivaibhav Apartment,

Near Sanjeevan Hospital, Sadarbazzar, Satara - 415 002, Maharahstra, India.

E-mail: swsipn@gmail.com

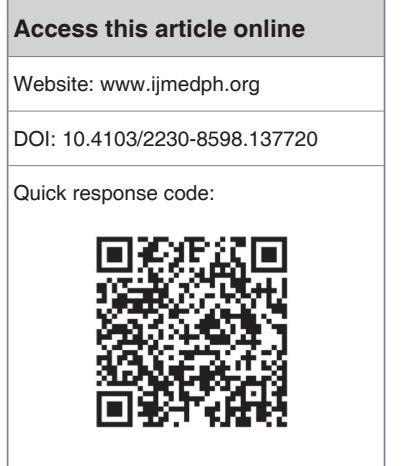

Background: Since 2007, Satara district is implementing a pilot project named "Second Honeymoon Package" (SHP). SHP gives cash incentives to encourage postponement of first pregnancy in newly married couples. At the same time, contraception services are also provided under National family welfare program. There requires a significant amount of commitment and expenditure from the beneficiaries to avail the benefits of governmental programs, which is often overlooked by the system. The costs of these two reproductive health interventions are compared in this study. Objective: To calculate the cost of providing and utilizing contraception services for the newly-wed couples in Satara district from the perspective of the Government of Maharashtra and that of beneficiaries'. Materials and Methods: This was a cost-minimization study of two reproductive health interventions in rural part of Satara district. Information about expenditure incurred was calculated from 17th June 2010 to 16th June 2012. Cost analysis was conducted from the perspective of Government of Maharashtra and that of beneficiaries'. Costs of SHP were evaluated in comparison with those of routine family welfare program. Results: One thousand and ninety-five out of 1355 participants $(80.8 \%)$ have used condoms, 125 participants (9.22\%) have used oral pills while only $15(1.1 \%)$ have used safe period method. The average distance of health facility from the homes of participants has been $4.24 \mathrm{~km} \pm 6.54$. Annual unit cost of implementation of SHP was Rs. 883 (16.35\$/ year) during the study period while the opportunity cost of utilizing the contraception services was Rs. 383.40 (7.1\$) per person per year. The annual unit cost of implementation of family planning program was Rs. 323.73 ( $6 \$$ ). Conclusions: In districts like Satara that have a strong family planning infrastructure, reorienting the program to provide contraception services for newly married couples may be achieved with minimal additional inputs.

Key words: Conditional cash transfer, cost-minimization study, opportunity cost, second honeymoon package, unit cost of contraception services

\section{INTRODUCTION}

Since 2007, Satara district is implementing a voluntary conditional cash transfer project named "Second Honeymoon Package" (SHP) with a corpus of Rs. 60 million from the National Rural Health Mission. If couples who have married after April 2007 and registered themselves with the zilla parishad and deferred having children for 2 years, they were promised an incentive of Rs. 5,000. Couples who opted to wait a third year would earn a total of Rs. 7,500. By the time the couple is enrolled for the benefit of postponement of first pregnancy and childbirth, their first honeymoon is already over. Their second honeymoon would commence after the desired period of postponement of first pregnancy. Hence the name "Second Honeymoon Package" is given to the scheme.

Overall, the evidence suggests that conditional cash transfer programs are effective in increasing the use of preventive services and sometimes improving health status. Further research is needed to clarify the cost effectiveness of conditional cash transfer programs and better understand which components play a critical role. The potential success and desirability of such programs in low-income settings, with more limited health system capacity, also deserves more investigation. ${ }^{[1]}$ 
There requires a significant amount of commitment and expenditure from the beneficiaries to avail the benefits of governmental programs, which is often overlooked by the system. Estimating the unit costs of health interventions is important to policy-makers for a number of reasons including the fact that the results can be used as a component in the assessment and improvement of the performance of their health systems. ${ }^{[2]}$ First, cost analysis helps to determine whether health services delivery deploy resources efficiently. Secondly, cost-analysis information from different locations can be compared. Thirdly, cost analysis would enable cost performance to be monitored over time. Fourthly, policy-makers can rely on cost-analysis information in determining how to standardize service delivery without compromising quality of care. Finally, cost analysis is important in determining reimbursement levels to hospitals funded by some form of health insurance. ${ }^{[3]} \mathrm{WHO}$ CHOICE project wants countryspecific estimates of unit costs of various health services over different time spans. ${ }^{[4]}$ Contraception services are also provided under National family welfare program. This paper compares the costs of these two reproductive health interventions.

\section{Objective}

To calculate the unit cost of providing and utilizing contraception services for the newly-wed couples in Satara district of Maharashtra (India) from the perspective of the government of Maharashtra and that of beneficiaries' using two reproductive health interventions.

\section{MATERIALS AND METHODS}

\section{Study design}

This was a cost-minimization study of two reproductive health interventions in rural part of Satara district of Maharashtra (India). Institutional ethics committee had given clearance wide its letter dated $12^{\text {th }}$ October 2010. Costs of SHP were evaluated in comparison with those of routine family welfare program. Effectiveness data was derived from a comprehensive review of literature. ${ }^{[1]}$

\section{Time horizon}

Information about expenditure incurred was calculated from 17 th June 2010 to 16 th June 2012.

\section{Perspective}

Cost analysis was conducted from the perspective of Government of Maharashtra and that of beneficiaries.

\section{Sampling and sample size}

Cases were the participants of SHP program while the controls were the couples residing in the same village as that of participants and married in the same season or year. Participants were selected by stratified random sampling. The strata being considered is Taluka (smaller administrative unit of the district). In the state of Maharashtra, there are 33 districts. In Satara district, there are
11 Talukas. Sample size was calculated using the formula $N=$ $4 \sigma^{2}(\mathrm{Zcrit}+\mathrm{Zpwr})^{2} / \mathrm{D}^{2}$. The minimum required sample size was 1,157 participants and the same number of controls. Considering the population of various Talukas in 2001 census, proportionate weightage was given to the acceptors and non-acceptors from each Taluka. Considering 10-15\% possible drop outs and Taluka-wise population, adequate sample size was selected.

\section{Data collection method}

Data collection schedule was filled up by duly trained Auxiliary nurse midwife (ANM) and multipurpose health workers (MPW). Training sessions were conducted by the researchers. Enquiries were made about the type of contraceptives used by the participants and controls. Enquiries were made about number and purpose of visits to the health centers, vehicle used for travelling, relation with and occupation of accompanying person, whether absence from work is required to avail the benefits of the program. Using recall questionnaire method; information was gathered from all sorts of health care workers like ANM, MPW, Health assistant (HA) and Medical officers (MO) about their monthly salary and working hours. Recall period was of 1 month. Information about how many days the health center was used for family planning /SHP program was collected. Costs were expressed as cumulative total costs during the time horizon.

Buildings of primary health centers and sub-centers at various places were used for program-related activities like distribution of contraceptives, counselling sessions, gathering of newly-wed couples, arrangement of felicitation ceremonies, etc. In the recall questionnaire, medical officers and other workers were asked to remember for how many days in last month their health center was used for program-related activities. Market rates of rental of buildings vary from place to place. So average rate was calculated and rental charge for those many days for which the center was used for program-related activities is calculated.

Program-related cost includes various sub-activities under SHP, e.g. 1 day Sensitization workshop at District/block level, printing of Certificates, purchasing pregnancy test kits, conducting focus group sessions, purchasing contraceptive material and supplies, felicitation functions, cash benefit under SHP, monitoring and evaluation. Various expenditure heads for each activity were vehicle fuel, electricity, stationary, food charges, consumables, internet, printing charges, photographs, rental of hall for felicitation ceremony, printing of flex banners, etc. While calculating costs in economic evaluation, all possible costing items must be considered and should be calculated if feasible. Felicitation ceremonies are useful in creating conducive atmosphere in favor of SHP and it serves as an advertisement of the program. It bestows praise and encourages successful couples and motivates others to accept the program. The interval between marriage and last menstrual period (LMP) for participants and controls was enquired. Data about successful postponements and eligibility for prize was collected. 


\section{Sources of data}

Secondary data includes SHP register, filled consent forms, cash books, financial management reports, monthly tour diaries, etc. Primary data came from pretested semi-open data collection schedule.

\section{Data analysis methods}

The resource consumption in health care sector includes contraceptive material, use of health center buildings, and value of time of health workers. These include not only the cost of providing the initial program but also all the continuing care cost (e. g., printing of forms, fuel charges, etc.). The patient and family resources consisted of out-of-pocket expenses in travelling to health centers, lost wages of beneficiaries and that of accompanying person. The formulae used for calculation were as follows.

1. Cost of each work hour of different workers = average salary/ average monthly working hours.

2. Manpower cost of each cadre of workers $=$ cost of each hour for that cadre * number of hours spent for particular program.

3. Rental cost of health center buildings $=\sum$ (Daily rent of each health center building at prevailing market rate $*$ number of days the building is used for the program.)

4. Lost wages of the participants $=\sum$ (Absence from work $*$ number of visits $*$ average daily wage rate).

a. Absence from work- If the visit is made according to convenience and absence from the work is not required then the co-efficient is 0 , otherwise the co-efficient is 1 . In this calculation public servants and unemployed persons are omitted. Public servants receive their wages even if they are absent from work. The loss of productivity in such cases is societal. Societal perspective is not analysed in this study. Similarly a person that is unemployed will not have lost some productivity because the alternative use of their time could not be for any economically productive venture.

b. Number of visits- Only the number of visits for the program-related work was accounted here.

c. Average daily wage rate- The participants may be manual laborers, semi-skilled business persons, service oriented or professional workers. Their average daily wage rate was used here in rupees term. The summation of multiplication of all these gave us the total cost of lost wages. Similarly the cost of lost wages by the accompanying person was calculated.

d. $\quad$ Travelling expenses $=\sum$ [Number of visits * average per kilometer rate for type of vehicle used $* 2$ (distance from health facility)]. The visits made to health facility for purpose other than contraception or program-related works were omitted.

\section{Discounting}

Data collection was conducted during 2010-11 and 2011-12 financial years. The costs were expressed using the base year of 2011-12 and $6.46 \%$ rate of discounting was applied to the rental costs of buildings, consumables and salary received in the financial year 2010-11. ${ }^{[5]}$ Besides these three categories, no capital expenditure was calculated in this study.

\section{RESULTS}

During the study period 1355 couples participating in SHP scheme and 1350 control couples were interviewed. Among the participants of the scheme and controls, condom was the most popular method, 1095 couples $(80.81 \%)$ used it. Followed by oral pills (9.22\%) couples, safe period method was employed by 15 to 51 couples and nine couples used copper $\mathrm{T}$ as a method of contraception. Difference between acceptors and controls regarding the use of different methods was statistically significant $(P<0.0001)$.

\section{Opportunity cost}

Female participants paid $6.51 \pm 7.25$ visits to the health facility during last 2 years. $(N=1355)$ Male participants paid $6.44 \pm 7.22$ visits during last couple of years. $(N=1303)(\mathrm{NS})$

Table 1 shows the reasons for visiting the health facility. $72.25 \%$ female and 59\% male participants visited the health facility for program-related reasons. Some participants had not visited the health facilities, but they were visited by the health workers in their homes. Only the visits paid for program-related reasons were included to calculate the costs incurred by the participants.

Table 2 shows the type of vehicle used to visit the health facility. Market rates prevalent in Satara district were used for each type of vehicle per kilometre of usage. The average distance of the health

\begin{tabular}{lcccc}
\hline \multicolumn{5}{l}{ Table 1: Reason of visiting the health facility } \\
\hline $\begin{array}{l}\text { Reason of visiting the } \\
\text { health facility }\end{array}$ & $\begin{array}{c}\text { Female } \\
\text { participants }\end{array}$ & $\%$ & $\begin{array}{c}\text { Male } \\
\text { participants }\end{array}$ & $\%$ \\
\hline Treatment, vaccination & 237 & 17.5 & 153 & 11.7 \\
Contraception & 443 & 32.7 & 426 & 32.7 \\
Program-related work & 536 & 39.6 & 343 & 26.3 \\
$\begin{array}{l}\text { Not visited the health } \\
\text { facilities }\end{array}$ & 139 & 10.3 & 381 & 29.2 \\
$N=$ & 1355 & & & \\
\hline
\end{tabular}

Chi square $=172.47$, D.F. $=3, P<0.0001$

\begin{tabular}{lcccc} 
Table 2: Type of vehicle used to visit health facility \\
\hline $\begin{array}{l}\text { Type of vehicle used to } \\
\text { visit the health facility }\end{array}$ & $\begin{array}{c}\text { Female } \\
\text { participants }\end{array}$ & $\begin{array}{c}\text { Male } \\
\text { participants }\end{array}$ & $\%$ \\
\hline Walking & 702 & 57.7 & 606 & 55.9 \\
Public transport & 268 & 22.0 & 232 & 21.4 \\
Two wheeler & 146 & 12.0 & 133 & 12.3 \\
Private four wheeler & 54 & 4.4 & 49 & 4.5 \\
Rickshaw & 42 & 3.5 & 26 & 2.4 \\
Launch & 1 & 0.1 & 1 & 0.1 \\
Bicycle & 3 & 0.2 & 38 & 3.5 \\
$N=$ & 1216 & & 1085 & \\
\hline
\end{tabular}

Chi square $=36.79$, D. F. $=6, P<0.0001$, Persons used more than one type of vehicles. 
facility from the homes of the participants was 4.24 kilometres with a standard deviation of 6.54 . This information was used to calculate the cost for the beneficiary to participate in this program.

Eight-hundred and twenty-nine (63.6\%) male participants and 432 $(31.9 \%)$ female participants required absence from their job in order to visit the health facility. It may be because, the holidays at the workplace coincide with holidays at health centers and furthermore males were better employed than females. Remaining participants managed to visit the health center as per their convenience.

Women need to be accompanied by someone while visiting the health facility. Table 3 shows who accompanies them during their visits. This information was used to calculate the lost wages of the accompanying person, in order to avail the benefits of the program. Information about the occupation of the escorting person was collected. $398(50.83 \%)$ were unemployed, 173 (22.09\%) were laborers, $148(18.9 \%)$ were in service, $58(7.41 \%)$ were in business, $1(0.13 \%)$ was professional, and $5(0.64 \%)$ were students. This information was used to calculate the wage loss incurred by the family of the participants.

Table 4 shows the wages lost by participants, their spouses and their escorting personnel and travelling expenses. Opportunity cost per person per year was Rs. 383.40 (7.1\$).

\section{Cost of implementing "Second honeymoon package"}

Table 5 shows that the cost of program implementation is Rs. 3341091/-.

\begin{tabular}{lcc} 
Table 3: Relationship with the escort & \\
\hline Accompanied by & Number of female participants & $\%$ \\
\hline Nobody & 433 & 35.61 \\
Husband & 543 & 44.65 \\
Brother/ sister in-law & 35 & 2.88 \\
Mother in law & 176 & 14.47 \\
Father in law & 19 & 1.56 \\
Parents & 8 & 0.66 \\
health workers & 2 & 0.16 \\
$N=$ & 1216 & \\
\hline
\end{tabular}

\begin{tabular}{|c|c|c|}
\hline Description & $\begin{array}{c}\text { Female } \\
\text { participant }\end{array}$ & $\begin{array}{c}\text { Male } \\
\text { participant }\end{array}$ \\
\hline $\begin{array}{l}\text { Cumulative lost wages (own) due } \\
\text { to scheme-related visits to health } \\
\text { facilities during the time horizon }\end{array}$ & Rs. 349000 & Rs. 975000 \\
\hline $\begin{array}{l}\text { Cumulative lost wages } \\
\text { (accompanying person) due to } \\
\text { scheme-related visits to health } \\
\text { facilities during the time horizon }\end{array}$ & Rs.611900 & Not applicable \\
\hline $\begin{array}{l}\text { Cumulative travelling expenses } \\
\text { during the time horizon }\end{array}$ & Rs.73404 & Rs. 68741 \\
\hline Opportunity cost & \multicolumn{2}{|c|}{ Rs.2078045 } \\
\hline Opportunity cost per person per year & \multicolumn{2}{|c|}{ Rs.383.40 (7.1\$) } \\
\hline
\end{tabular}

Table 6 shows various components of cost of implementing the SHP program. Total cost of implementation of SHP was Rs. 47,86,052. By dividing it by the total number of participants, unit cost was calculated. Annual cost per person was Rs. 883 (16.35\$/year).

\section{Cost of implementing family planning program (Comparator)}

Family planning program had many components such as laparoscopic tubal ligation, abdominal tubal ligations, vasectomies and copper $\mathrm{T}$ insertions; which were generally not consumed by the newly-wed couples. So only distribution of condom, oral pills, cost of work hours by the health personnel, rental of the days for which health center building was used for family planning work was taken into consideration.

Table 7 shows that the annual unit cost of implementation of family planning program was Rs. 323.73(6\$). The interval between marriage and last menstrual period (LMP) for participants was 569.13 days with a standard deviation of 413.57 days. This interval approximates the duration of postponement of first pregnancy. Controls could postpone their first pregnancy by 353.89 days with a standard deviation of 273.18 days. When this difference was subjected to two-tailed unpaired $\mathrm{T}$ test, it was found to be highly significant $(P<0.0001)$. There were 704 couples out of 1355 participants $(51.95 \%)$ who had postponed their pregnancy for more than 2 years. They were eligible to get the cash prize of Rs. 5000/-. Sixhundred and fifty-one couples could not postpone their pregnancy by at least 2 years and were not eligible for the prize. This gave the success rate of $51.95 \%$.

\section{DISCUSSION}

In our study, considering the reproductive span of women as 25 years; the lifetime cost comes to $408.8 \$$ for SHP and $150 \$$ for routine FP. Babigumira JB, et al. have implemented a hypothetical new contraceptive program (NCP) from both societal and governmental perspectives in Uganda. Mean lifetime cost per woman from the governmental perspective has been $636 \$$ for $\mathrm{NCP}$ vs. $685 \$$ for current contraceptive program (CCP). These findings agree with those in the present study. They have concluded that universal access to modern contraceptives in Uganda appears to be highly cost effective and increasing contraceptive coverage should be considered among Uganda's public health priorities. ${ }^{[6]}$

Second honeymoon program employs two modalities for service delivery. ANM and MPW provide counseling and contraceptives during their home visits and participants were also expected to attend health centers for medical consultations and urine pregnancy test. Similarly Routh S and Barkat EK compared three modalities; conventional home visits, Community service point (CSP) strategy where services were provided by female health workers from points in the community like school, clubs etc. rather than at home, third strategy provides services from a static primary health care clinic (PHCC). They concluded that neither of the two alternative 


\begin{tabular}{|c|c|c|c|c|c|c|c|}
\hline Activity & Participants & Period & $\begin{array}{l}\text { Vehicle } \\
\text { fuel (Rs.) }\end{array}$ & $\begin{array}{c}\text { Consumables } \\
\text { (Rs.) }\end{array}$ & $\begin{array}{l}\text { Lunch, } \\
\text { food (Rs.) }\end{array}$ & $\begin{array}{l}\text { Miscellaneous } \\
\text { (Rs.) }\end{array}$ & $\begin{array}{l}\text { Total } \\
\text { (Rs.) }\end{array}$ \\
\hline $\begin{array}{l}\text { One day Sensitization } \\
\text { workshop at District } \\
\text { level. }\end{array}$ & $\begin{array}{l}\text { Distrct level officers, } \\
\text { medical officers and } \\
\text { supervisors. }(n=210)\end{array}$ & Oct-10 to Mar-11 & 9311 & 1600 & 6250 & 7855 & 25016 \\
\hline $\begin{array}{l}\text { One day Sensitisation } \\
\text { workshops at Taluka } \\
\text { level. }\end{array}$ & $\begin{array}{l}\text { Health Supervisors, MPW, } \\
\text { ANM, Anganwadi workers } \\
(n=2220)\end{array}$ & $\begin{array}{l}\text { January to March } \\
\qquad 2011\end{array}$ & 27540 & 21000 & 297000 & 60317 & 405857 \\
\hline Printing of Certificate & $\begin{array}{l}\text { For couples accepting the } \\
\text { Scheme. }\end{array}$ & Apr-11 & & 0 & 0 & 59500 & 59500 \\
\hline Pregnancy test kits. & $\begin{array}{l}\text { For ANM, Anganwadi } \\
\text { workers and PHC } \\
(987 @ \text { Rs. 30) }\end{array}$ & Mar-11 to Mar-12 & & 29610 & 0 & 0 & 29610 \\
\hline $\begin{array}{l}\text { Focus group- } 29 \\
\text { sessions }\end{array}$ & $\begin{array}{l}\text { Opinion leaders, } \\
\text { beneficiaries, health workers }\end{array}$ & Jun-11 to Feb-12 & & 10000 & 11300 & & 21300 \\
\hline Material and Supplies & $\begin{array}{l}\text { Condom, OP, IEC material, } \\
\text { etc. (1355 @ Rs. 1000) }\end{array}$ & Apr-11 to Mar-12 & & 0 & 0 & 0 & 1355000 \\
\hline $\begin{array}{l}\text { Felicitation Function } \\
\text { Taluka level }\end{array}$ & $\begin{array}{l}\text { Contingent expenditure for } \\
11 \text { functions }\end{array}$ & Dec-11 & 2200 & 2950 & 10700 & 4620 & 20470 \\
\hline Honeymoon Package & $\begin{array}{l}\text { Benefit to } 280 \text { couples @ } \\
\text { Rs. } 5000 \text { each. }\end{array}$ & Dec-11 & & 0 & 0 & 0 & 1400000 \\
\hline $\begin{array}{l}\text { Monitoring and } \\
\text { Evaluation }\end{array}$ & $\begin{array}{l}\text { Field visits of district level } \\
\text { officers }\end{array}$ & Jun-11 & 7980 & 6680 & 0 & 9678 & 24338 \\
\hline Grand total & & & & & & 3341091 & \\
\hline
\end{tabular}

\begin{tabular}{|c|c|c|}
\hline Sub-head & Unit & $\begin{array}{l}\text { Cost in } \\
\text { Rupees }\end{array}$ \\
\hline \multirow{4}{*}{$\begin{array}{l}\text { a. Cumulative manpower cost for } 1355 \\
\text { couples served amongst } 50000 \text { newly } \\
\text { married couples during the time horizon }\end{array}$} & 319 ANMs & 518694 \\
\hline & $232 \mathrm{MPWs}$ & 240057 \\
\hline & $116 \mathrm{MOs}$ & 195734 \\
\hline & 119 HAs & 169178 \\
\hline \multirow{2}{*}{$\begin{array}{l}\text { b. Cumulative rental cost at prevailing market } \\
\text { rates of buildings during the time horizon }\end{array}$} & $65 \mathrm{PHCs}$ & 84552 \\
\hline & 273 SCs & 236746 \\
\hline $\begin{array}{l}\text { c. Cumulative program cost of SHP } \\
\text { (Please refer to Table number } 5 \text { ) }\end{array}$ & \multicolumn{2}{|c|}{ Rs.3341091 } \\
\hline Cost for the group $=a+b+c$ & \multicolumn{2}{|c|}{ Rs.4786052 } \\
\hline $\begin{array}{l}\text { Cost per person per year (Participant } \\
\text { husbands and wives per year) }\end{array}$ & \multicolumn{2}{|c|}{ Rs.883 (16.35\$/ year) } \\
\hline
\end{tabular}

\begin{tabular}{|c|c|c|}
\hline Sub-head & Unit & Cost in Rupees \\
\hline \multirow[t]{4}{*}{ a. Cumulati } & 319 ANMs & 159396 \\
\hline & 232 MPWs & 73216 \\
\hline & $116 \mathrm{MOs}$ & 48542 \\
\hline & 109 HAs & 60198 \\
\hline \multirow{3}{*}{$\begin{array}{l}\text { b. Cumulative rental cost of health } \\
\text { center buildings for family planning } \\
\text { program during the time horizon }\end{array}$} & 65 PHCs & 30086 \\
\hline & $15 \mathrm{RH}$ & 16200 \\
\hline & 173 SCs & 10530 \\
\hline \multicolumn{2}{|l|}{$\begin{array}{l}\text { c. Material and Supplies (Condom, } \\
\text { Oral Pills, publicity material, vehicle } \\
\text { fuel charges, contingency, etc.) } \\
\text { consumed during the time horizon }\end{array}$} & 1350000 \\
\hline $\begin{array}{l}\text { Expenditure for } 1350 \text { couples for } \\
\text { Family Planning program }=a+b+c\end{array}$ & \multicolumn{2}{|c|}{ Rs. $17,48,167$} \\
\hline $\begin{array}{l}\text { Cost Per person per year (Controls, } \\
\text { both husbands and wives per year) }\end{array}$ & \multicolumn{2}{|c|}{ Rs.323.73 (6\$) } \\
\hline
\end{tabular}

strategies proved detrimental to overall program performance, although they were easier to administer. ${ }^{[7]}$

SHP utilized the services of Paramedical andnon-medical workers to deliver the messages and contraceptives. Multipurpose workers and Auxiliary nurse midwives were educated up to $10^{\text {th }}$ standard and after that they were trained in health care delivery. Most of them were the residents of the same village. Kim CR and Free C found that there was no significant difference in condom use for groups who received peer led interventions compared with controls. They concluded that overall findings did not provide convincing evidence that peer led educational interventions improved sexual outcomes for adolescents. These findings are in contradiction to our study. SHP demonstrated that counseling by ANM and MPW help to increase the uptake of contraceptives. This may be because the former studies were conducted in developed countries and all their subjects were not married. ${ }^{[8]}$ Reaching married adolescents can be cost efficient, may be introduced at scale, and is sometimes less controversial than introducing programs for unmarried youth. In countries that have a strong family planning infrastructure, reorienting the program to reach married adolescents may be achieved with minimal inputs. In Bangladesh, Pathfinder has found that reorienting family planning workers to conduct outreach work to serve married adolescents would be required minimal additional resources. The strategy could be brought to scale quickly by grafting services for newlyweds onto already-existing family planning programs, achieving broad coverage of newlywed couples within a few years of program initiation..$^{[9]}$

Mavranezouli I has compared long acting reversible contraceptive (LARC) with oral contraceptive pills and female sterilization for the prevention of pregnancy. The four LARC methods have been 
Copper T, Levonorgestrel intra uterine system, etonorgestrel and depot medroxy progesterone acetate injection. They have found that all LARC methods have been more effective and less costly than the oral contraceptive pills. In the SHP, LARC methods have not been offered to the participants. These methods should be and can be incorporated in SHP in future. ${ }^{[10]}$ Nakhaee $\mathrm{N}$ et al. have examined oral contraceptives, male condoms, injectable contraceptives and intra-uterine devices. The effectiveness analysis has showed that the highest adjusted conventional couple years of protection have been achieved with Intra Uterine Devices and condoms. They have concluded that male condoms turned out to be the most expensive strategy, while contraceptive implants represented the least costly method of contraception. In the present study the most frequently used method is male condoms. ${ }^{[1]}$ Salaries are the major cost component in this and various other studies. ${ }^{[3]}$

Trussell $\mathrm{J}$ et al., have examined cost effectiveness of various female and male contraceptive strategies compared with no contraception in the general population. They have concluded that all the contraceptive strategies have been more effective and less costly than no method. ${ }^{[12]}$ This finding differs from that in our study. In our study the comparator has been the top priority 'National family welfare program'. We have not compared SHP with "Do nothing" strategy. Chiou CF et al., have conducted economic analysis of contraceptives for women in the United States, from the health care services payer's perspective (third party payer). They estimated the annual cost range of $329-439 \$$ per person. This is quite costly than those in the present study. This may be because of exorbitantly costly health system based on health insurance in USA. ${ }^{[13]}$

\section{CONCLUSIONS}

One thousand and ninety-five out of 1355 participants (80.8\%) have used condoms, 125 participants $(9.22 \%)$ have used oral pills while only $15(1.1 \%)$ have used safe period method. The average distance of health facility from the homes of participants has been $4.24 \mathrm{~km}$ \pm 6.54 . For $702(57.7 \%)$ participants, the health center has been at walk able distance, while the remaining participants either possesses own vehicle or have access to public transport. Annual unit cost of implementation of SHP was Rs.883 (16.35\$/ year) during the study period while the cost of utilizing the contraception services was Rs.383.40 (7.1\$) per person per year. The annual unit cost of implementation of family planning program was Rs. 323.73 (6\$). In districts like Satara that have a strong family planning infrastructure, reorienting the program to provide contraception services for newly married couples may be achieved with minimal additional inputs.

\section{REFERENCES}

1. Lagarde M, Haines A, Palmer N. Conditional cash transfers for improving uptake of health interventions in low- and middle-income countries: A systematic review. JAMA 2007;298:1900-10.

2. Hutubessy RC, Baltussen RM, Torres-Edejer TT, Evans DB. Generalised cost-effectiveness analysis: An aid to decision making in health. Appl Health Econ Health Policy 2002;1:89-95.

3. Aboagye AQ, Degboe AN, Obuobi AA. Estimating the cost of healthcare delivery in three hospitals in southern ghana. Ghana Med J 2010;44:83-92.

4. WHO | WHO-CHOICE [Internet]. WHO. Available from: http://www.who. int/choice/en/ [Last accessed on 2013 Oct 15].

5. India Inflation Rate | Actual Value | Historical Data | Forecast [Internet]. Available from: http://www.tradingeconomics.com/india/inflation-cpi [Last accessed on 2013 Oct 15].

6. Babigumira JB, Stergachis A, Veenstra DL, Gardner JS, Ngonzi J, Mukasa-Kivunike $\mathrm{P}$, et al. Potential cost-effectiveness of universal access to modern contraceptives in Uganda. PLoS One 2012;7:e30735.

7. Routh S, Barkat-e-Khuda. An economic appraisal of alternative strategies for the delivery of $\mathrm{MCH}-\mathrm{FP}$ services in urban Dhaka, Bangladesh. Int $\mathrm{J}$ Health Plann Manage 2000;15:115-32.

8. Kim CR, Free C. Recent evaluations of the peer-led approach in adolescent sexual health education: A systematic review. Perspect Sex Reprod Health 2008;40:144-51.

9. Simon C, Hainsworth G, Barros RDB de. Reaching Newlywed and Married Adolescents [Internet]. Available from: http://www.pathfinder.org/ publications-tools/Reaching-Newlywed-and-Married-Adolescents.html [Last accessed on 2013 Oct 15].

10. Mavranezouli I. LARC Guideline Development Group. The costeffectiveness of long-acting reversible contraceptive methods in the UK: Analysis based on a decision-analytic model developed for a National Institute for Health and Clinical Excellence (NICE) clinical practice guideline. Hum Reprod 2008;23:1338-45.

11. Nakhaee N, Mirahmadizadeh AR, Gorji HA, Mohammadi M. Assessing the cost-effectiveness of contraceptive methods in Shiraz, Islamic Republic of Iran. East Mediterr Health J 2002;8:55-63.

12. Trussell J, Leveque JA, Koenig JD, London R, Borden S, Henneberry J, et al. The economic value of contraception: A comparison of 15 methods. Am J Public Health 1995;85:494-503.

13. Chiou CF, Trussell J, Reyes E, Knight K, Wallace J, Udani J, et al. Economic analysis of contraceptives for women. Contraception 2003;68:3-10.

How to cite this article: Lale SV, Pratinidhi AK. Unit cost of providing and utilizing contraception services for newly married couples in Satara district of Maharashtra, India. Int J Med Public Health 2014;4:292-7.

Source of Support: Nil, Conflict of Interest: None declared. 